\title{
ART use and associated factors among HIV positive caregivers of orphans and vulnerable children in Tanzania
}

\author{
Amon Exavery ${ }^{1 *} \mathbb{D}$, John Charles $^{1}$, Asheri Barankena ${ }^{1}$, Erica Kuhlik², Godfrey M. Mubyazi ${ }^{3}$, Kassimu Tani ${ }^{1}$, Amal Ally ${ }^{1}$,
} Epifania Minja ${ }^{1}$, Alison Koler ${ }^{1}$, Levina Kikoyo ${ }^{1}$ and Elizabeth Jere ${ }^{1}$

\begin{abstract}
Background: Utilization of antiretroviral therapy (ART) is crucial for better health outcomes among people living with the human immunodeficiency virus (PLHIV). Nearly 30\% of the 1.6 million PLHIV in Tanzania are not on treatment. Since HIV positive status is the only eligibility criterion for ART use, it is critical to understand the obstacles to ART access and uptake to reach universal coverage of ART among PLHIV. For the caregivers of orphans and vulnerable children (OVC) LHIV and not on ART, attempts to identify them and ensure that they initiate and continue using ART is critical for their wellbeing and their ability to care for their children.

Methods: Data are from the community-based, United States Agency for International Development (USAID)funded Kizazi Kipya project that aims at scaling up the uptake of HIV/AIDS and other health and social services by orphans and vulnerable children (OVC) and their caregivers. HIV positive caregivers of OVC who were enrolled in the USAID Kizazi Kipya project between January 2017 and June 2018 were included in this cross-sectional study. The caregivers were drawn from 11 regions: Arusha, Iringa, Katavi, Kigoma, Mara, Mbeya, Morogoro, Ruvuma, Simiyu, Singida, and Tanga. The outcome variable was ART status (either using or not), which was enquired of each OVC caregiver LHIV at enrollment. Data analysis involved multivariable analysis using random-effects logistic regression to identify correlates of ART use.
\end{abstract}

Results: In total, 74,999 caregivers living with HIV with mean age of 44.4 years were analyzed. Of these, $96.4 \%$ were currently on ART at enrollment. In the multivariable analysis, ART use was 30\% lower in urban than in rural areas (adjusted odds ratio $(\mathrm{OR})=0.70,95 \%$ confidence interval $(\mathrm{Cl}) 0.61-0.81$ ). Food security improved the odds of being on ART (OR $=1.29,95 \% \mathrm{Cl} 1.15-1.45)$. Disabled caregivers were $42 \%$ less likely than non-disabled ones to be on ART $(\mathrm{OR}=0.58,95 \% \mathrm{Cl} 0.45-0.76)$. Male caregivers with health insurance were $43 \%$ more likely than uninsured male caregivers to be on ART (OR=1.43,95\% Cl 1.11-1.83). Caregivers aged 40-49years had 18\% higher likelihood of being on ART than the youngest ones. Primary education level was associated with $26 \%$ increased odds of being on ART than no education ( $\mathrm{OR}=1.26,95 \% \mathrm{Cl} 1.13-1.41)$.

(Continued on next page)

\footnotetext{
* Correspondence: aexavery@pactworld.org

${ }^{1}$ Pact, P.O. Box 6348, Dar es Salaam, Tanzania

Full list of author information is available at the end of the article
}

C C The Author(s). 2020 Open Access This article is licensed under a Creative Commons Attribution 4.0 International License, which permits use, sharing, adaptation, distribution and reproduction in any medium or format, as long as you give appropriate credit to the original author(s) and the source, provide a link to the Creative Commons licence, and indicate if changes were made. The images or other third party material in this article are included in the article's Creative Commons licence, unless indicated otherwise in a credit line to the material. If material is not included in the article's Creative Commons licence and your intended use is not permitted by statutory regulation or exceeds the permitted use, you will need to obtain permission directly from the copyright holder. To view a copy of this licence, visit http://creativecommons.org/licenses/by/4.0/ The Creative Commons Public Domain Dedication waiver (http://creativecommons.org/publicdomain/zero/1.0/) applies to the data made available in this article, unless otherwise stated in a credit line to the data. 
(Continued from previous page)

Conclusions: Although nearly all the caregivers LHIV in the current study were on ART (96.4\%), more efforts are needed to achieve universal coverage. The unreached segments of the population LHIV, even if small, may lead to worse health outcomes, and also spur further spread of the HIV epidemic due to unachieved viral suppression. Targeting caregivers in urban areas, food insecure households, who are uninsured, and those with mental or physical disability can improve ART coverage among caregivers LHIV.

Keywords: Utilization, Antiretroviral therapy, HIV, Caregivers of orphans and vulnerable children, Kizazi Kipya, Tanzania

\section{Background}

In 2018, the global estimate of the number of people living with HIV was 37.9 million, 62\% (23.3 million) of whom were accessing antiretroviral therapy (ART) [1]. Corresponding estimates of people living with HIV (PLHIV) were 20.6 million and 67\% (13.8 million) on ART in Eastern and Southern Africa together [2]. In Tanzania, 1.6 million people were living with HIV in 2018, 71\% of whom were accessing ART [3]. The use of ART by people living with HIV (PLHIV) is crucial for better health outcomes: ART decreases HIV-associated morbidity and mortality, as well as the incidence of new HIV infections [4].

In 2016, the World Health Organization (WHO) removed all barriers for ART eligibility, and recommended that all PLHIV should start ART early after undergoing confirmatory test for HIV ('Test and Treat'), regardless of the WHO clinical stage or CD4 count [5]. The early use of ART keeps PLHIV alive and healthier, and ART significantly reduces the risk of onward transmission of HIV, as shown in a real-world setting in sub-Saharan Africa [6]. However, evidence shows that not all PLHV are on treatment, including those who know that they are infected with HIV $[1-3,7]$. This suggests that barriers to ART use among PLHIV remain, necessitating further research and programming to address them and achieve universal ART coverage.

Tanzania introduced an ART program for HIV care and treatment in 2004. Since then, HIV/AIDS-related morbidity and mortality have been declining, quality of life of PLHIV improved, and the majority of PLHIV have resumed normal life [8]. The Government of Tanzania (GoT) in collaboration with development partners and civil society organizations (CSOs) has continued to scale up HIV/AIDS care and treatment services. As of 2017, up to $82.1 \%$ of all 7494 health facilities in the country offered care and treatment services to PLHIV. The GoT has also been working tirelessly to increase human resources as well as medical supplies and commodities. Furthermore, the GoT improves retention and adherence to ART through community engagement using community volunteers to support care and treatment services and minimizing loss to follow up (LTFU). In this case, more than 350 treatment advocates, 1002 community action teams and 213 cluster coordination teams have been formed and trained to support PLHIV on care [8].

Accordingly, the goals of the Tanzania Health Sector HIV and AIDS Strategic Plan IV, 2017-2022 (HSHSP IV) Monitoring and Evaluation Plan are geared to maximizing efforts and coverage of HIV prevention and treatment services, particularly for key and vulnerable populations [9]. These populations, according to the national HIV/AIDS response, are Female Sex Workers (FSW), People who Inject Drugs (PWID), Men who have Sex with Men (MSM), Adolescents Girls and Young Women (AGYW), fishers and fishing community, miners, agricultural plantations workers, long distance truck drivers, construction workers and students in higher learning institutions [8]. While individual caregivers of orphans and vulnerable children (OVC) may fall into one of these categories, as a group they are not identified as a key and vulnerable population despite their HIV risk factors and related health, social, and economic challenges in caring for OVC.

In 2014, the UNAIDS proposed the 90-90-90 targets, which called for a scale-up of HIV testing, so that by 2020, 90\% of all PLHIV are aware of their status; $90 \%$ of all people with diagnosed HIV infection receive sustained ART; and $90 \%$ of all people receiving ART achieve viral suppression [4]. This analysis builds off the second 90, whereby, although data on HIV burden and ART coverage among OVC caregivers does not yet exist, in the general adult PLHIV population (age 15 years and above) in Tanzania, HIV prevalence is $4.7 \%$ and ART use among those who know their HIV positive status is 93.6\% [10]. However, looking at ART coverage among all PLHIV in Tanzania, only $71 \%$ were on treatment at the end of 2018 [3]. Although the country has made considerable progress towards achievement of the UNAIDS 90-90-90 targets in adults [10], further efforts are needed to get all PLHIV on ART because the future of the HIV epidemic will be driven by those fewer individuals who are not on treatment [11]. Therefore, research efforts are still needed to identify, understand, and suggest measures to take to reaching universal coverage of ART among PLHIV. 
Barriers to ART access and use among PLHIV in developing countries have been well documented. The most commonly cited barriers to ART use among PLHIV in the developing world are stigma and the distance between place of residence and the health facility [7, 12-15]. Also, lower ART coverage among men than women (68\% vs. $71 \%)$, and among youth under 30 years than those aged $30-59$ years (58\% vs. $75 \%$ ) were observed in KwaZulu-Natal, South Africa, implying that sex and age are important demographic factors playing a role in ART coverage [16]. Furthermore, a recent qualitative systematic review in low- and middle-income countries (LMICs) observed the following reasons for ART nonuse: feeling healthy, low social support, gender norms, difficulties translating intentions into actions, high care-seeking costs, concerns about confidentiality, low quality health services, recommended lifestyle changes, and incomplete knowledge of treatment benefits [7]. Similarly, barriers to ART access in terms of fear to start ART due to drug shortages at health facilities, staffing shortages, and lack of social and economic support were identified in Uganda [14], as well as fear of HIV disclosure, women's lack of support from male partners, demanding work schedules, and high transport costs [15]. Male gender, younger age, living alone or in households with one to two co-residents, and CD4 count of more than 250 cells per microliter of blood were significantly associated with non-enrollment into free community HIV care in Uganda [17].

In Tanzania, a qualitative study carried out in Iringa Region found significant barriers inhibiting retention to care and treatment for PLHIV. The observed barriers include lack of knowledge and general misconception about treatment, access problems such as difficulties in reaching distant clinics and pervasive poverty that render PLHIV unable to cope with out-of-pocket financial costs associated with HIV treatment, persistent stigmatization of PLHIV, and reliance on alternative healing [18]. The factors perceived to enhance HIV treatment with ART were positive perceptions among the clients of the efficacy of ART, improved ART availability, improved access to care through supplemental aid, and social support [18]. Despite these observations, quantitative and large-scale evaluations are needed to demonstrate statistically representative evidence of conditions and contexts which influence ART use to reach universal coverage of ART among PLHIV.

In assessing the influence of family and social support given to PLHIV, it was observed that while OVC are a well-researched population [19-26], their caregivers have not been prioritized in studies. To date, HIV burden, treatment coverage and health outcomes are not well known among the caregivers. Caregivers play a significant role in the lives and wellbeing of OVC and the entire family, including managing HIV treatment for children LHIV [27]. Research shows that most caregivers have to face economic and food insecurity challenges as a result of additional children to feed and clothe due to AIDS-related orphanhood [28]. Many HIV-affected caregivers do not earn enough income to adequately care for their families [28-30]; they struggle to find safe, affordable childcare, and often corrode their incomegenerating activities (IGAs) due to caregiving tensions [31]. Since poor health of caregivers results in poor health of their children, strategies to support OVC should target the caregiver-child dyad [32]. For the caregivers LHIV and not on ART, attempts to identify them and ensure that they initiate and continue using ART is critical for their wellbeing and their ability to care for their children. Thus, an improved understanding of the health, social, economic, and psychological challenges faced by the caregivers can inform programs to enhance their ability to be more responsive to their own needs and those of their children [33]. This study explored the extent of and factors associated with ART use among OVC caregivers LHIV in Tanzania. As the country strives for universal health coverage (UHC), knowledge of the factors will alight the high burden subpopulations that should be targeted with additional support so that all PLHIV are ultimately initiated and sustained on ART for better health outcomes and accelerating an end to the HIV epidemic [11]. The government, programs, donors, CSOs and other stakeholders including research communities can benefit from this knowledge to properly plan or advance interventions. Ultimately, with improved policies and programs, ART access and uptake can be scaled among this population and indirectly benefit their children too.

\section{Methods}

\section{Source of data}

Data for this study stem from the community-based, USAID-funded Kizazi Kipya project (2016-2021) in Tanzania, which aims to increase the uptake of ageappropriate HIV-related and other health and social services for improved health and wellbeing by OVC, adolescents and their families. The study used caregivers' selfreported data collected by Community Case Workers (CCWs) during beneficiary screening and enrollment into the project using the Family and Child Asset Assessment (FCAA) tool from January 2017 to June 2018. CCWs are a government cadre of volunteers trained on the National Integrated Case Management System (NICMS) to provide services to OVC and their caregivers [34]. The USAID Kizazi Kipya project works through this cadre to provide doorstep services to OVC and their caregivers. The project supports the CCWs with a monthly stipend for their work. The caregivers 
were enrolled into the project if their households met one or more of the 14 household vulnerabilities related to HIV presented in Table 1.

Following beneficiary screening and enrollment, the USAID Kizazi Kipya project develops a care plan for each caregiver and their OVC in the household. The project then provides or links caregivers, children and adolescents to services in the areas of health, nutrition, education, child protection, social protection, and economic strengthening. No material support is provided. The project provides psychosocial support, nutrition assessments, counseling and support, referrals and linkages, and care plan monitoring.

To ensure data quality, the USAID Kizazi Kipya project assigned a unique identification number (UID) to each beneficiary enrolled in the project. The project also developed electronic data management systems to track services provided across multiple service delivery points and merge with assessment and demographic data using the UID. These systems have enabled the analysis conducted for this study. Enhanced data validation and logic checks are implemented in the electronic data systems to ensure that appropriate services are provided to the appropriate beneficiaries (e.g. based on age, sex, HIV status etc.) [35].

The project provides supportive supervision to the CCWs through Lead Case Workers (LCWs) and Para Social Workers (PSWs) who offer them mentorship and coaching, and also follow up with them to ensure proper service delivery, timely completeness and correctness of forms and timely submission of data. Each CCW reports

Table 1 USAID Kizazi Kipya Project household screening and enrollment criteria

\footnotetext{
1. Household is headed by child (under 18 years old)

2. Household is headed by an elderly caregiver (60 years or older)

3. Household cares for one or more single or double orphan

4. Caregiver is chronically ill and unable to meet basic needs of children

5. Caregiver is a drug user

6. Caregiver or adolescent aged 10-19 years in the household is a sex worker

7. One or more adolescent girls aged 10-19 years are sexually active

8. Adolescent girl age 10-19 years in the household is pregnant or has a child

of her own

9. One or more household members are HIV positive

10. One or more children in the household have tuberculosis

11. One or more children in the household are severely malnourished

12. One or more children in the household have been or are abused or at risk for abuse

13. One or more children are living and or working on the streets, and

14. One or more children in the household are working in mines.
}

to a CSO which also provides supportive supervision to the CCWs through Case Management Coordinators (CMCs). The CSOs provide refresher trainings and conduct monthly meetings with CCWs to discuss performance, challenges, best practices and way forward. Both LCWs and CCWs are supervised by an assigned government social welfare officer at ward level to ensure that services provided and their quality are in accordance with the government guidelines and standards [36, 37]. The USAID Kizazi Kipya project is further described elsewhere [38].

\section{Study area}

This study is based on new beneficiary enrollment data from 39 districts (known locally as councils) in 11 regions of Tanzania where the USAID Kizazi Kipya project conducted beneficiary screening and enrollment activities from January 2017 to June 2018. The regions were: Arusha, Iringa, Katavi, Kigoma, Mara, Mbeya, Morogoro, Ruvuma, Simiyu, Singida, and Tanga.

\section{Study design}

This is a cross-sectional secondary analysis of existing program data of the USAID Kizazi Kipya project. FCAA data were collected during screening and enrollment of beneficiaries into the project. Beneficiaries in households meeting at least one of the enrollment criteria listed in Table 1 and voluntarily consented to participate in the project were enrolled. After enrollment, beneficiaries were followed up by the project over time with a variety of health, education and other social services.

\section{Study population}

This study was based on 74,999 caregivers of OVC who reported that they were living with HIV at the time of screening and enrollment into the USAID Kizazi Kipya project. Caregivers who reported that they were not living with HIV as well as those who did not disclose their HIV status to the project volunteers were excluded. A caregiver is a guardian who has the greatest responsibility for the daily care and rearing of one or more OVC in a household [37]. A caregiver is not necessarily a biological parent of the OVC in that household.

\section{Variables}

The outcome variable for this study is caregivers' ART use status at enrollment as dichotomized to 'not on ART (0)' and 'on ART (1)'. Caregivers LHIV whose ART status was unknown or not responded, were excluded from the analysis.

Independent variables included were sex, age, marital status, education attained, place of residence (rural or urban), household food security (i.e. whether any household member went $24 \mathrm{~h}$ without eating due to lack of 
food three or more times in the last 4 weeks), health insurance status, mental or physical disability status, and household wealth quintile.

Wealth quintile was constructed using principal component analysis (PCA) of household assets to obtain household socio-economic status [39]. Five wealth quintiles were constructed, ranging from the lowest quintile (Q1) for the poorest households, to the highest quintile (Q5) for the well-off households. The household assets included in the PCA process were; dwelling materials (brick, concrete, cement, aluminium and/or other material), livestock (chicken, goats, cows, and others), transportation assets (bicycle, motorcycle/moped, tractor, motor vehicle, and others), and productive assets (sewing machine, television, couch or sofa, cooking gas, hair dryer, radio, refrigerator, blender, oven, and others).

\section{Data analysis}

The process of data analysis began with exploratory analysis that involved one-way tabulations to obtain distributional features of the data, from which frequency distribution tables were generated. Then cross-tabulations of ART status by each independent variable were performed using the Chi-Square test to assess the significance of the association between ART status and each independent variable.

Multivariable analysis was conducted using multilevel modelling through random-effects logistic regression to identify factors associated with ART use. The value of a multilevel model lies in the fact that it simultaneously considers data hierarchies (e.g. village-level, householdlevel or individual-level factors), while allowing for nonindependence of observations within groups [40, 41]. For the current study, the multilevel model was fitted considering two levels: individual-level and village-level. Higher levels such as district and region were not statistically justified for inclusion (i.e. very low intraclass correlation coefficients [42]), suggesting independence of observations in those levels. The model was chosen to account for clustered structure of the data [43]. Clustering of caregivers was assumed at a village-level. Specifically, we assumed that caregivers LHIV who live in the same village may be correlated with respect to ART use because they may be likely to share the same sources of, barriers to, and enablers of ART use. Independent factors associated with ART use were inferred at a significance level of $5 \%$ or less.

Furthermore, the multivariable analysis involved the construction of three models. The first model comprised the entire study population of 74,999 OVC caregivers. The remaining models broke down the study population by sex: the second model was for 54,170 female OVC caregivers, and the third model was for 20,829 male OVC caregivers. These approaches (i.e. multivariable analysis and stratification) played a roles as strategies to address confounding [44-47] among others. Also, stratification by sex provides a deeper understanding of how correlates of ART use differ by gender and inform appropriate interventions that are responsive to the unique needs of each gender [48-50]. For example, one study in Zambia observed that while poverty-related factors hampered ART uptake in women, side effects and social pressure attributable to masculinity did so in men [49]. This would not have been observed without stratification by gender.

\section{Results}

\section{Background characteristics}

As presented in Table 2, this study was based on 74,999 HIV positive OVC caregivers, $96.4 \%$ of whom were on ART. These caregivers were from 5532 villages in Tanzania. The average age of the caregivers was 44.4 years (standard deviation $[\mathrm{SD}]=11.7$ ) and the majority were female (72.2\%). Nearly half (48.7\%) of respondents were married, and the majority had attained primary education (78.9\%). Nearly one fifth (17.6\%) of the caregivers had never attended school. Rural residences accounted for $63.1 \%$ of caregivers, and those from food insecure households were $14.6 \%$.

\section{ART use by background characteristics}

Table 3 presents the percent of caregivers LHIV who were currently on ART at the time of enrollment in the USAID Kizazi Kipya project by their background characteristics. The proportion of the HIV positive caregivers who were on ART varied significantly by some background characteristics. The proportion of caregivers LHIV who were on ART was $95.2 \%$ among the oldest (60+ years) as compared to $96.7 \%$ among those who were aged 40-49 $(p<0.001)$. ART use was higher among those in marital unions (96.7\%) than among those widowed $(96.0 \%)(p=0.001)$. ART use was $95.6 \%$ among caregivers who had never been to school, $96.6 \%$ among those who had primary education, and $95.8 \%$ among those who had secondary or higher education $(p<$ 0.001). ART use also varied by wealth quintile, whereby the lowest level was $95.8 \%$ among caregivers in the middle quintile, and the highest level was $97.2 \%$ among those who were in the second quintile $(p<0.001)$. ART use was higher in rural areas than in urban areas $(96.7 \%$ versus $96.0 \%)(p<0.001)$. Food security was also a significant dimension of ART use, whereby ART use was higher among caregivers from food secure households (96.6\%) than those in food insecure households (95.3\%) $(p<0.001)$. ART use was higher among caregivers with health insurance than those without it $(96.9 \%$ versus $96.3 \%)(p=0.005)$. Finally, ART use was as low as $93.4 \%$ among caregivers with mental or physical disability and 
Table 2 Frequency distribution of HIV positive caregivers of orphans and vulnerable children in Tanzania, $2018(N=74,999)$

\begin{tabular}{lll}
\hline Covariate & $\begin{array}{l}\text { Number of HIV positive } \\
\text { caregivers }(\mathrm{n})\end{array}$ & Percent (\%) \\
\hline Overall & $\mathbf{7 4 , 9 9 9}$ & $\mathbf{1 0 0 . 0}$
\end{tabular}

\section{ART status}

$\begin{array}{lll}\text { Not on ART } & 2699 & 3.6 \\ \text { On ART } & 72,300 & 96.4\end{array}$

\section{Caregiver sex}

$\begin{array}{lll}\text { Female } & 54,170 & 72.2 \\ \text { Male } & 20,829 & 27.8\end{array}$

\section{Age group (in Years)}

$\begin{array}{ll}19-29 & 5883 \\ 30-39 & 21,401 \\ 40-49 & 25,643 \\ 50-59 & 13,665 \\ 60+ & 8407 \\ \text { Mean = 44.4, SD }=11.7 & -\end{array}$

Marital status

$\begin{array}{ll}\text { Married or living together } & 36,525 \\ \text { Divorced or separated } & 12,447 \\ \text { Never been married } & 5336 \\ \text { Widowed } & 20,691\end{array}$

\section{Education attained}

$\begin{array}{ll}\text { Never been to school } & 13,191 \\ \text { Primary } & 59,182 \\ \text { Secondary or higher } & 2626\end{array}$

\section{Wealth Quintile}

$\begin{array}{ll}\text { Lowest (Q1) } & 19,763 \\ \text { Second } & 12,165 \\ \text { Middle } & 13,232 \\ \text { Fourth } & 14,437 \\ \text { Highest (Q5) } & 15,402\end{array}$

Place of residence

$\begin{array}{ll}\text { Rural } & 47,305 \\ \text { Urban } & 27,694\end{array}$

\section{Household food security status}

$\begin{array}{ll}\text { Insecure } & 10,940 \\ \text { Secure } & 64,059\end{array}$

Family has health insurance (CHF/TIKA)?

$$
\begin{array}{ll}
\text { No } & 63,673 \\
\text { Yes } & 11,326
\end{array}
$$

Mentally or physically disabled?

\begin{tabular}{lll} 
No & 73,872 & 98.5 \\
Yes & 1127 & 1.5 \\
\hline
\end{tabular}

CHF Community Health Fund, TIKA Tiba kwa Kadi
Table 3 Percent of HIV positive caregivers of orphans and vulnerable children who were currently on ART at enrollment by background characteristics in Tanzania, $2018(N=74,999)$

\begin{tabular}{lll}
\hline Covariate & $\begin{array}{l}\text { \% of HIV positive caregivers } \\
\text { currently on ART }\end{array}$ & ${ }^{*} \boldsymbol{P}$-value \\
\hline Overall & $\mathbf{9 6 . 4}$ & - \\
Caregiver sex & & 0.348 \\
$\quad$ Female & 96.4 & \\
$\quad$ Male & 96.3 &
\end{tabular}

Age group (in Years) $\quad<0.001$

$19-29$

30-39 96.6

40-49 96.7

$50-59-96.5$

$60+\quad 95.2$

Marital status

0.001

Married or living together 96.7

Divorced or separated $\quad 96.4$

Never been married $\quad 96.2$

Widowed 96.0

Education attained

$<0.001$

Never been to school $\quad 95.6$

Primary 96.6

Secondary or higher $\quad 95.8$

Wealth Quintile

$<0.001$

Lowest (Q1) $\quad 96.1$

Second $\quad 97.2$

Middle $\quad 95.8$

Fourth $\quad 96.2$

Highest (Q5) $\quad 96.9$

Place of residence

$<0.001$

Rural $\quad 96.7$

Urban 96.0

Household food security $\quad<0.001$ status

Insecure $\quad 95.3$

Secure 96.6

Family has health insurance $\quad 0.005$

(CHF/TIKA)?

No 96.3

Yes 96.9

Mentally or physically

$<0.001$

\begin{tabular}{lc} 
No & 96.5 \\
Yes & 93.4 \\
\hline${ }^{*} p$-values are based on Pearson's & Chi-Square test
\end{tabular}


as high as $96.5 \%$ among caregivers without any of the disabilities $(p<0.001)$.

\section{Results from multivariable analysis}

In Table 4, adjusted odds ratios (OR) and their corresponding 95\% confidence intervals (CI) of the factors associated with ART use among caregivers LHIV are presented, accounting for the random effects. Based on this context, the following interpretations are made: In the overall model, age was a significant predictor of ART use only for the age group $40-49(\mathrm{OR}=1.18,95 \% \mathrm{CI}$ 1.00-1.40). The effect of age on ART use was clearer in the stratified analysis, whereby ART use was 30\% less likely among the oldest female caregivers than the youngest females (female age 60+: $\mathrm{OR}=0.70,95 \%$ CI 0.56 0.87 ). On the other hand, the likelihood of ART use increased with age among male caregivers (male age 3039: $\mathrm{OR}=1.63$, 95\% CI 1.13-2.35; male age 40-49: OR = 2.04, 95\% CI 1.42-2.92; male age 50-59: OR $=2.14,95 \%$ CI 1.47-3.12; and male age $60+$ : OR $=1.71,95 \%$ CI 1.16 , 95\% CI 1.16-2.52).

HIV positive caregivers with primary education were $26 \%$ more likely to be on ART than those who had never attended school $(\mathrm{OR}=1.26,95 \% \mathrm{CI} 1.13-1.41)$. This effect was maintained for both female caregivers $(\mathrm{OR}=$ 1.27, 95\% CI 1.12-1.45) and male caregivers $(\mathrm{OR}=1.30$, 95\% CI 1.04-1.62). Similarly, secondary education or higher was associated with higher likelihood of ART use, but the effect was not statistically significant.

Wealth quintile was associated with ART use in a mixed fashion. Generally, caregivers in higher wealth quintiles were associated with a lower likelihood of ART use than the lowest quintile, with the exception of the second quintile in which caregivers were $39 \%$ more likely to be on ART than the lowest quintile $(\mathrm{OR}=1.39$, 95\% CI 1.20-1.61). In the stratified models, women exhibited the same pattern of ART use as the overall group, but in men, the second, fourth and the highest wealth quintiles suggested increased likelihood of ART use, though only the second quintile showed significance $(\mathrm{OR}=1.98,95 \%$ CI 1.42-2.78).

Caregivers living in urban areas were $30 \%$ less likely to be on ART than their rural counterparts (OR $=0.70,95 \%$ CI 0.61-0.81). This finding was consistent for female caregivers $(\mathrm{OR}=0.69,95 \%$ CI $0.59-0.80)$ and male caregivers $(\mathrm{OR}=0.72$, 95\% CI 0.56-0.91). Caregivers living in food secure households were $29 \%$ more likely to be on ART than those in food insecure households (OR $=1.29,95 \%$ CI 1.15-1.45). While the direction and significance of the effect remained, the magnitude was lowest $(\mathrm{OR}=1.23$, 95\% CI 1.07-1.41) in females and highest in males (OR = 1.61, 95\% CI 1.28-2.03). Caregivers with health insurance were $19 \%$ more likely to be on ART than those without it (OR $=1.19,95 \%$ CI 1.04-1.36). This effect was statistically significant among male caregivers $(\mathrm{OR}=1.43,95 \% \mathrm{CI}$ $1.11-1.83)$, but not in female caregivers $(\mathrm{OR}=1.09,95 \%$ CI 0.94-1.28). The presence of mental or physical disability was associated with a $42 \%$ lower likelihood of being on ART $(\mathrm{OR}=0.58,95 \%$ CI $0.45-0.76)$. The direction and significance of the effect remained, but the magnitude was lowest $(32 \%)$ in female $(\mathrm{OR}=0.68,95 \%$ CI $0.48-0.97)$ and highest (63\%) in male caregivers $(\mathrm{OR}=0.37,95 \%$ CI 0.23 $0.58)$.

The intraclass correlation coefficient (ICC) suggested that $40 \%$ of the variability in ART use was due to residence of the caregivers in the same village $(\mathrm{ICC}=0.40)$. This was 40 and $44 \%$ in female and male caregivers, respectively.

\section{Discussion}

This study assessed the extent of, and factors associated with ART utilization among HIV positive caregivers of OVC in Tanzania. Results showed that $96.4 \%$ of all the 74 , 999 caregivers who reported that they were LHIV were on ART at enrollment. This proportion was high and slightly exceeded the national estimate of $93.6 \%$ as the proportion of adults aged 15 years and older LHIV who are on ART [10], which reflects the considerable progress the Government of Tanzania has made in linking PLHIV to treatment services. Although this level of ART use nears universal coverage for people who are aware of their HIV status, the current efforts need to be accelerated because the future of the HIV epidemic and its associated morbidities will be driven by the small segments of the infected populations who are not reached with and sustained on HIV treatment.

In the multivariable analysis, several caregiver characteristics showed significant association with ART use. Caregivers aged $40-49$ years were $18 \%$ more likely to be on ART than the younger ones in the age group 19-29 years. The higher likelihood of being on ART as age advanced was clearer for men, since men in all higher age groups were significantly more likely to be on ART than those in the youngest age group, 19-29 years. Although this observation was consistent with others in Uganda [17] and South Africa [16], the underlying mechanism was not clear, hence a need for further research. On the other hand, the current study also observed that female HIV positive caregivers age $60+$ years were $30 \%$ less likely to be on ART than their counterparts in the youngest age group. While this suggests a clear need for targeted strategies to enhance ART uptake among female elderly caregivers, it was also not clear why this was the case. More studies are required to further explore this association.

Caregivers with primary education level were more likely than those who had never been to school to be on ART. This was also the case in both male and female caregivers in the stratified analysis. However, although 
Table 4 Multivariable random-effects logistic regression of factors associated with ART utilization in HIV positive caregivers of orphans and vulnerable children in Tanzania, 2018

\begin{tabular}{|c|c|c|c|c|c|c|}
\hline \multirow[t]{3}{*}{ Covariate } & \multicolumn{2}{|c|}{ All $(\boldsymbol{N}=74,999)$} & \multicolumn{2}{|c|}{ Women $(\boldsymbol{N}=54,170)$} & \multicolumn{2}{|c|}{ Men $(\boldsymbol{N}=20,829)$} \\
\hline & \multirow{2}{*}{$\begin{array}{l}\text { Odds } \\
\text { ratio } \\
\text { (OR) }\end{array}$} & $95 \%$ Confidence Interval (Cl) & \multirow{2}{*}{$\begin{array}{l}\text { Odds } \\
\text { ratio } \\
\text { (OR) }\end{array}$} & 95\% Confidence Interval (Cl) & \multirow{2}{*}{$\begin{array}{l}\text { Odds } \\
\text { ratio } \\
\text { (OR) }\end{array}$} & 95\% Confidence Interval (CI) \\
\hline & & Upper Limit & & Upper Limit & & Lower Limit \\
\hline
\end{tabular}

\section{Caregiver sex}

$\begin{array}{llll}\text { Female } & 1.00 & - & - \\ \text { Male } & 0.92 & 0.83 & 1.02\end{array}$

\section{Age group (in Years)}

$19-29$
$30-39$
$40-49$
$50-59$
$60+$

$\begin{array}{lllll}1.00 & - & - & 1.00 & - \\ 1.11 & 0.94 & 1.31 & 1.05 & 0.87 \\ * *_{1.18} & 1.00 & 1.40 & 1.06 & 0.88 \\ 1.16 & 0.97 & 1.39 & 0.99 & 0.80 \\ 0.86 & 0.71 & 1.04 & { }^{* *} 0.70 & 0.56\end{array}$

\section{Marital status}

Married or living together

Divorced or separated

Never been married

Widowed

\subsection{0}

$0.96 \quad 0.85$

$0.91 \quad 0.77$

$0.95 \quad 0.85$

Education attained

Never been to schoo

Primary

Secondary or higher

$\begin{array}{ll}1.00 & - \\ * * * 1.26 & 1.13 \\ 1.09 & 0.86\end{array}$

1.41

1.38

Wealth Quintile

\section{Lowest (Q1)}

Second

Middle

Fourth

Highest (Q5)

Place of residence

Rural

Urban

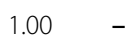

***1.39 1.20

${ }^{* *} 0.84 \quad 0.74$

${ }^{* *} 0.88 \quad 0.77$

$0.98 \quad 0.85$
${ }^{* * *} 0.70 \quad 0.61$

Household food security status

Insecure

Secure

$1.00 \quad-$

***1.29 1.15

1.45

Family has health insurance (CHF/TIKA)?

$$
\begin{array}{lll}
\text { No } & 1.00 & - \\
\text { Yes } & * * 1.19 & 1.04
\end{array}
$$

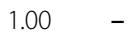

Mentally or physically disabled?

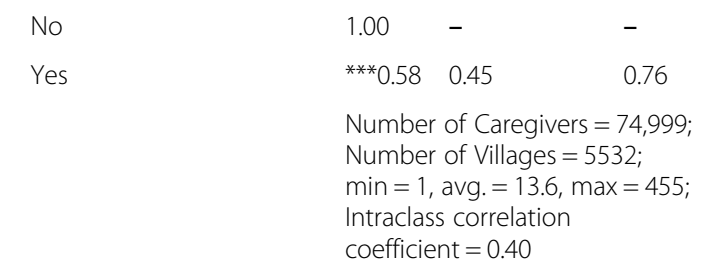

$\begin{array}{ll}1.00 & - \\ 0.93 & 0.81 \\ { }^{*} 0.84 & 0.70 \\ 0.95 & 0.84\end{array}$

$0.95 \quad 0.84$

1.27

1.28

1.22

0.87 
there was an increased likelihood of ART use among caregivers with secondary education or higher, the increase was not statistically significant. It is possible that people with at least some education are more likely to comprehend the value of ART, thus use it to stay healthy. Also, they may be at a better position to understand the instructions for using ART. A recent systematic review concluded that incomplete knowledge of the benefits ART was a reason for ART nonuse [7]. Another study in Brazil observed late ART initiation due to low education levels [51]. Therefore, encouraging formal education attainment even at the primary level, is likely to improve ART uptake and possibly other health and social services. Education can reduce treatment misconceptions as well as the use of alternative healing [18], which are not scientifically proven to improve health outcomes in PLHIV.

HIV positive caregivers residing in urban areas were less likely than their rural counterparts to be on ART. However, there are many studies showing higher likelihood of ART utilization in urban areas than in rural areas [52-54]. Although the infrastructural, health and social service conditions of rural and urban settings are greatly diverse, with a generally better condition in urban settings than rural ones, especially in low- and middle-income countries [55], confounders such as cultural and behavioral factors associated with rural compared with urban settings may explain these differences in ART uptake. Rural populations have been reported to be more communal than urban populations [56]. This may be one of the likely routes for better social support structures which are key to ART use [7, 55, 57]. While more studies may be needed to explain the mechanisms through which ART use and rural-urban residences are related, overall, there is a need to tailor interventions to the specific needs of each area [58] to ensure that all PLHIV are on treatment.

Food security was a significant determinant of ART use in the HIV positive caregivers, whereby those from food secure households were more likely to be on ART than those from food insecure households. This observation remained significant in the stratified analysis for both female and male caregivers. This observation is consistent with many others which have established that lack of food is a significant barrier to ART utilization and adherence $[14,55,58-60]$. People may be hesitant to start ART if they do not intend to stay on it due to such reasons as lack of food. This suggests that integrating food support into HIV programs may improve coverage of ART in PLHIV, especially those with limited access to sufficient food.

The results showed an increased likelihood of ART use among caregivers with health insurance than those without, especially for male caregivers. It has been observed that health insurance increases the probability of seeking care [61], and plays a substantial role in increasing access to facility-based care [62]. The variability in ART use by health insurance ownership suggests presence of reasons other than costs because ART is free in Tanzania. One's decision to acquire health insurance may be a function of knowledge and or perceived usefulness, thus a sign of good healthseeking behavior [63]. One possibility for this observation could be that, as caregivers access their insurance-enabled health services, they may also have to disclose their HIV status to the health provider, thus attracting HIV-related counselling and treatment services for their overall wellbeing. Therefore, while expanding the coverage of health insurance is required to facilitate access to health services, this is likely to encourage ART use among PLHIV. This may be a useful strategy, among others, for enhanced ART coverage among caregivers LHIV, especially men. Men are more likely than women to demonstrate poor health behavior, such as late ART initiation [64], thus necessitating targeted support. This is further supported by the results which demonstrate a stronger relationship between health insurance and ART use among men than women. This may be due to less need for insurance among women than men: women generally demonstrate stronger health seeking behavior than men, and combined with the free ART distribution, may be less influenced by insurance to take up ART than their male counterparts.

The current study also found that OVC caregivers LHIV who were physically or mentally disabled were significantly less likely to be on ART than those without the disabilities. These findings held true through the stratified analyses, among both male and female caregivers. Similar studies have linked mental health with HIV treatment uptake [65, 66], but the influence of physical disability is unknown. There may be physical and logistical challenges to ART access among disabled PLHIV, thus a need for programs to target the disabled with interventions to improve ART use among them. It has been noted that physical or mental disabilities attract the attention of non-disabled persons, often triggering prejudices, and discriminatory behaviors. Therefore, the presence of disability and disease can lead nondisabled to avoid contact with the disabled or even to engage in making antisocial comments or actions [67]. This, in most cases, results into self-stigma [68], a phenomenon that has been associated with poor use of ART in PLHIV [7, 14, 15].

Wealth quintile was also a significant predictor of ART use among the OVC caregivers. Those in the second wealth quintile were more likely to be on ART than those in the lowest wealth quintile. This was the case overall, as well as among male and female caregivers. However, higher wealth quintiles (i.e. middle and fourth) were significantly associated with lower likelihoods of ART use in the overall model as well as in women. The middle and fourth wealth quintiles were not significant 
in the men's model, but the fifth wealth quintile was associated with higher likelihood of ART use than the lowest quintile. These disparities in ART use between male and female caregivers in the middle through fifth wealth quintiles were not clear, thus a need for further research to clarify the observed relationship. Overall, other studies have observed higher likelihood of ART use with better economic status [7, 14, 57, 58, 69].

Finally, as the intra-class correlation coefficient (ICC) indicated, there was a significant clustering of the HIV positive caregivers at village level, whereby up to $40 \%$ of the variability in ART use among them was due to residence in the same village. This indicated that there may be closer social interactions and communication among the caregivers who reside in the same village, thus likely to behave similarly with respect to ART use. This, somehow, can be shaped by the possibility that these people may be receiving ART from the same facility. Also, they may be facing similar environmental obstacles or enablers to ART use, such as distance to facility, which may further explain the relationship. It has been observed that social support from the family, friends or peers (which is more likely among those in the same vicinity) is an important dimension of ART use $[7,55,57,70]$.

\section{Limitations}

The data were self-reported by the caregivers, allowing for the possibility of recall or information bias in the data. To minimize this, the CCWs who conducted the screening and enrollment exercise were trained to probe the caregivers for accuracy in responding to the questions.

\section{Conclusions}

ART use among OVC caregivers who report their HIV positive status in Tanzania is high (96.4\%) and predicted by age, formal education attainment, place of residence, food security, health insurance, mental or physical disability, and wealth status. Since a few caregivers reporting their HIV positive status remain unreached, to achieve universal ART coverage in this population, interventions and policy guidelines should address the observed demand-side barriers such as older age (60 years and above) for female caregivers, and below 30 years for male caregivers; education level, particularly those who have never been to school as they may be having difficulties comprehending ART value for their health. Health providers should be trained to communicate about ART use to low-education patients to improve ART initiation among them. Other barriers that may be integrated in HIV programming activities include urban residences, food insecurity, lack of health insurance particularly for men, and mental or physical disability. Although there may be a few caregivers LHIV who are disabled, as well as those unlikely to be on ART in other subgroups, it is equally crucial to understand this and plan how to reach them because global emphasis to ending the HIV/AIDS epidemic requires leaving no one behind - testing and treating all [71]. This implies that, high burden subpopulations represent the ultimate future of the HIV epidemic, unless targeted efforts are timely made to ensure universal coverage of care and treatment services.

\begin{abstract}
Abbreviations
AIDS: Acquired immunodeficiency syndrome; ART: Antiretroviral therapy; CD4: Cluster of differentiation 4; CHF: Community health fund;

Cl: Confidence interval; FCAA: Family and child asset assessment; HIV: Human immunodeficiency virus; ICC: Intra-class correlation coefficient; LHIV: Living with HIV; LMICs: Low- and middle-income countries; MRCC: Medical Research Coordinating Committee; MUAC: Mid-upper arm circumference;

NIMR: National Institute for Medical Research; OR: Adjusted odds ratio; OVC: Orphans and vulnerable children; PCA: Principal component analysis; PLHIV: People living with HIV; SD: Standard deviation; TIKA: Tiba kwa Kadi; UHC: Universal health coverage; UNAIDS: Joint United Nations Programme on HIV/AIDS; USAID: United States Agency for International Development
\end{abstract}

\section{Acknowledgements}

We acknowledge the project staff, the consortium partners implementing the USAID Kizazi Kipya Project, Civil Society Organizations (CSOs), Community Case Workers (CCW) and District Social Welfare Officers (DSWO).

\section{Authors' contributions}

AE conceptualized the problem, conducted statistical analyses, reviewed the literature, and drafted the manuscript. JC participated in problem refinement, design, statistical analyses, and critical review of the manuscripts. EK critically reviewed the manuscript for intellectual content and advised on the structure. $A B, G M M, K T, A A, E M, A K, L K$, and $E J$ critically reviewed the manuscripts for intellectual content. All authors read and approved the final draft of the manuscript.

\section{Authors' information}

$\mathrm{AE}$ is a professional hands-on Biostatistician with over 10 years of experience in quantitative data analyses, health research, and program monitoring and evaluation in Tanzania. He has extensively worked in the areas of HIV/AIDS, reproductive, maternal, newborn, and child health (RMNCH), and sexual and reproductive health $(\mathrm{SRH})$. He holds an MSc in Medicine in Population-based Field Epidemiology from the University of the Witwatersrand, Johannesburg, and a bachelor's degree in Statistics from the University of Dar es Salaam in Tanzania. He currently coordinates Research and Learning activities for Pact's USAID Kizazi Kipya (New Generation) Project - the largest OVC program in Tanzania.

$\mathrm{JC}$ is a seasoned Monitoring and Evaluation specialist with extensive expertise and experience in development planning and results-based monitoring and evaluation that he has been acquired in a career spanning over 10 years of working in international agencies. He has over the years built up expertise and experience in providing leadership and technical input in the design and operationalization of the M\&E systems for both facility and community-based programs including HIV prevention, Maternal and Newborn Health, HTC, Family Planning, Pre-Service Education and Supply Chain Management and Logistics for public health commodities. He has been with Pact Tanzania since August 2016 as the Monitoring and Evaluation Director for the USAID Kizazi Kipya Project providing technical leadership in the design and implementation of the project's monitoring and evaluation and learning plan and information systems to track progress against targets and achievement of outcomes and impact.

$A B$ is a Medical Doctor by training, and Public Health specialist with nine years of experience in HIV/AIDS programing; cutting across clinical and community interventions in Tanzania. He now serves as Senior Technical Advisor (STA) for Pact's USAID Kizazi Kipya project in Tanzania. He has a passion to serve the least privileged populations, particularly children in the most vulnerable environment.

EK is a monitoring and evaluation professional who holds a Masters of Science in Public Health degree from the Johns Hopkins Bloomberg School of Public Health. She has 10 years of public health and international development experience with expertise in monitoring and evaluation, research, HIV/AIDS, OVC programs, malaria, and health education and 
communication. She currently works for Pact headquarters in Washington, DC and provides M\&E support to Pact Tanzania and the USAID Kizazi Kipya project.

GMM is working with the National Institute for Medical Research as a Principal Research Scientist, and heading the Department of Health Systems \& Policy Research, with over 40 publications in health matters. He is a Health Economist, holding a PhD in Health Sciences from the University of Copenhagen, an MA in Health Management, Planning \& Policy from the University of Leeds, UK, an MBA in Accounting and Finance from the Kampala International University, Uganda, BA in Economics from the University of Dar es Salaam, Tanzania, a Diploma in Research Methodology from the DBL Centre for Health Research and Development in Denmark, and now continuing with LLB degree course at the Open University of Tanzania. $K T$ is a Research and Learning Officer, working with Kizazi Kipya Project at Pact Tanzania, responsible for data analysis, interpretation and research products dissemination. He has worked on health research for more than 10 years and area of focus was on maternal and child health, health financing, costing and economic evaluations. He was trained in economics and specialized in health system and policy research.

AA is an MPH candidate at the Muhimbili University of Health and Allied Sciences (MUHAS) and a holder of bachelor's degree in Medical Sociology from the University of Dar es Salaam (UDSM) in Tanzania. She has 12 years of work experience in Monitoring and Evaluation in community, household and facility level interventions, and currently serves as a Senior Monitoring and Evaluation Officer for Pact's USAID Kizazi Kipya project in Tanzania. Previously, she worked in the fields of HIV prevention, Maternal, Newborn and Child Health, Infection Prevention, HTC, Family Planning, Pre-Service Education, Cervical Cancer and Control and OVC programs.

EM is a holder of an MSc. degree in Life Sciences and Engineering (Food and Nutritional Sciences) from The Nelson Mandela African Institution of Science and Technology (NM-AIST), and a BSC. Home economics and Human Nutrition from Sokoine University of Agriculture (SUA). She has 14 years of work experience in management of development projects, and currently serves as a National level Economic Strengthening Officer for Pact's USAID Kizazi Kipya project in Tanzania. Previously, she worked in the fields of women economic empowerment, health research, and human nutrition. She is an expert in maternal and child nutrition as well as management of community savings and lending groups. She is a member of professional societies including African women in Agriculture research and development (AWARD), with extensive professional network within and beyond Tanzania. AK holds a Master of Public Health degree from Columbia University Mailman School of Public Health. She has over 12 years of technical and project management experience, including 8 years working oversees in East and Southern Africa on donor-funded health programs. She has worked on a range of public health issues including HIV/AIDS, Maternal, Neonatal and Child Health (MNCH), Orphans and Vulnerable Children (OVC), Water, Sanitation and Hygiene (WASH), and Non-Communicable Diseases (NCDs) and with a variety of donors including USAID, CDC, Global Fund, Bill \& Melinda Gates Foundation, Hilton Conrad Foundation, Chevron, and Coca-Cola. LK is a Technical Director of the USAID Kizazi Kipya Project at Pact, Tanzania. The program serves over 1 million orphans, vulnerable children, youth and their caregivers at risk of, or are affected/infected by the HIV/AIDS pandemic. She has worked on children, women and other vulnerable groups for over 20 years. She is a social and public health expert and she hold a Bachelor of Laws from the University of Dar es salaam and a master's degree in Business Administration from ESAMI/Maastricht school of Management.

EJ has a Master of Public Health degree and 20 years of experience working on various health and HIV projects in East and Southern Africa. She currently works for Pact Tanzania as the Chief of Party on the USAID Kizazi Kipya project, a PEPFAR funded project focused on expanding community level services for orphans and vulnerable children (OVC)

\section{Funding}

No direct funding was received for the purpose of producing this manuscript. However, data used are from the USAID Kizazi Kipya, a five-year project (July 2016 to June 2021) in Tanzania with funding from the U.S. President's Emergency Plan for AIDS Relief (PEPFAR) through the United States Agency for International Development (USAID). The contents of this paper; the study design, data collection, analysis, and interpretation; and the manuscript's writing remain the sole responsibility of the authors and do not necessarily reflect the views of USAID or the United States Government.

\section{Availability of data and materials}

This study is based on data from the USAID Kizazi Kipya project (2016-2021) in Tanzania. Pact Tanzania is the prime organization implementing the project, hence owns the data. The datasets analyzed during the current study are not publicly available due to confidentiality restrictions pertaining to records of the project beneficiaries, but are available from Pact Tanzania on reasonable request.

\section{Ethics approval and consent to participate}

Ethics approval was received from the Medical Research Coordinating Committee (MRCC) of the National Institute for Medical Research (NIMR) in Tanzania with certificate number NIMR/HQ/R.8a/Nol.IX/3024. Screening and enrollment of beneficiaries into the USAID Kizazi Kipya Project was entirely voluntary. The FCAA tool was completed only after each participant signed a statement of an informed consent. CCWs are always available during their regular household visits to answer questions or concerns which the project beneficiaries may have. Access to the datasets analyzed for this study can be provided by Pact Tanzania, and there may be no need to apply for another ethics approval.

\section{Consent for publication}

Not applicable.

\section{Competing interests}

The authors declare that they have no competing interests.

\section{Author details}

${ }^{1}$ Pact, P.O. Box 6348, Dar es Salaam, Tanzania. ${ }^{2}$ Pact, Inc., 1828 L St NW Suite 300, Washington, DC 20036, USA. ${ }^{3}$ National Institute for Medical Research (NIMR), P.O Box 9653, Dar es Salaam, Tanzania.

\section{Received: 21 February 2020 Accepted: 9 August 2020}

Published online: 17 August 2020

\section{References}

1. UNAIDS. Global HIV \& AIDS statistics - 2019 fact sheet. 2019. Available from: https://www.unaids.org/en/resources/fact-sheet. Cited 2019 Jul 25

2. UNAIDS. Fact sheet - Global AIDS update 2019. 2019. Available from: https:// www.unaids.org/sites/default/files/media_asset/UNAIDS_FactSheet_en.pdf. Cited 2019 Jul 29.

3. UNAIDS. Country factsheets. United Republic of Tanzania; 2018. Available from: https://www.unaids.org/en/regionscountries/countries/ unitedrepublicoftanzania. Cited 2019 Jul 29.

4. UNAIDS. 90-90-90: an ambitious treatment target to help end the AIDS epidemic. Geneva: UNAIDS Joint United Nations Programme on HIV/AIDS; 2014. Available from: https://www.unaids.org/sites/default/files/media_asset/ 90-90-90_en_0.pdf. Cited 2019 Jun 20.

5. World Health Organization. Consolidated guidelines on the use of antiretroviral drugs for treating and preventing HIV infection: recommendations for a public health approach. 2016. Available from: http:// apps.who.int/iris/bitstream/10665/208825/1/9789241549684_eng.pdf. Cited 2019 Jul 29

6. Vandormael A, Newell M-L, Bärnighausen T, Tanser F. Use of antiretroviral therapy in households and risk of HIV acquisition in rural KwaZulu-Natal, South Africa, 2004-12: a prospective cohort study. Lancet Glob Health. 2014; 2(4):e209-15.

7. Ahmed S, Autrey J, Katz IT, Fox MP, Rosen S, Onoya D, et al. Why do people living with HIV not initiate treatment? A systematic review of qualitative evidence from low- and middle-income countries. Soc Sci Med. 2018;213: 72-84.

8. Tanzania Commission for AIDS (TACAIDS). National HIV and AIDS response report for 2017 - Tanzania Mainland. 2018. Available from: http://library. tacaids.go.tz/bitstream/handle/123456789/134/National\%20HIV\%20and\%2 OAIDS\%20Response\%20Report\%20for\%202017\%20-\%20Tanzania\%2 OMainland.pdf? sequence=1\&isAllowed=y. Cited 2020 Mar 27.

9. National AIDS Control Programme. Tanzania Health Sector HIV and AIDS Strategic Plan IV, 2017-2022 (HSHSP IV) monitoring and evaluation plan. Dar es Salaam: Ministry of Health, Community Development, Gender, Elderly and 
Children; 2018. Available from: https://www.measureevaluation.org/resources/ publications/tr-18-302/at_download/document. Cited 2020 Mar 27.

10. Tanzania Commission for AIDS (TACAIDS), Zanzibar AIDS Commission (ZAC). Tanzania HIV Impact Survey (THIS) 2016-2017: final report. Dar es Salaam; 2018. Available from: https://www.nbs.go.tz/nbs/takwimu/this2016-17/ THIS_2016-2017_Final_Report.pdf. Cited 2018 Sep 18.

11. Frank TD, Carter A, Jahagirdar D, Biehl MH, Douwes-Schultz D, Larson SL, et al. Global, regional, and national incidence, prevalence, and mortality of HIV, 1980-2017, and forecasts to 2030, for 195 countries and territories: a systematic analysis for the global burden of diseases, injuries, and risk factors study 2017. Lancet HIV. 2019;6(12):e831-59.

12. Posse M, Meheus F, Asten HV, Ven AVD, Baltussen R. Barriers to access to antiretroviral treatment in developing countries: a review. Tropical Med Int Health. 2008;13(7):904-13.

13. Govindasamy D, Ford N, Kranzer K. Risk factors, barriers and facilitators for linkage to antiretroviral therapy care: a systematic review. AIDS. 2012;26(16): 2059-67.

14. Bajunirwe F, Tumwebaze F, Akakimpa D, Kityo C, Mugyenyi P, Abongomera G. Towards 90-90-90 target: factors influencing availability, access, and utilization of HIV services-a qualitative study in 19 Ugandan Districts. BioMed Res Int. 2018; Available from: https://www.hindawi.com/journals/ bmri/2018/9619684/. Cited 2019 Jul 29.

15. Nakigozi G, Atuyambe L, Kamya M, Makumbi FE, Chang LW, Nakyanjo N, et al. A qualitative study of barriers to enrollment into free HIV care: perspectives of never-in-care HIV-positive patients and providers in Rakai, Uganda. BioMed Res Int. 2013;2013:470245.

16. Huerga H, Van Cutsem G, Ben Farhat J, Puren A, Bouhenia M, Wiesner L, et al. Progress towards the UNAIDS 90-90-90 goals by age and gender in a rural area of KwaZulu-Natal, South Africa: a household-based community cross-sectional survey. BMC Public Health. 2018;18(1):303.

17. Nakigozi G, Makumbi F, Reynolds S, Galiwango R, Kagaayi J, Nalugoda F, et al. Non-enrollment for free community HIV care: findings from a population-based study in Rakai. Uganda AIDS Care. 2011;23(6):764-70.

18. Tomori C, Kennedy CE, Brahmbhatt H, Wagman JA, Mbwambo JK, Likindikoki S, et al. Barriers and facilitators of retention in HIV care and treatment services in Iringa, Tanzania: the importance of socioeconomic and sociocultural factors. AIDS Care. 2014;26(7):907-13.

19. Huy BV, Teeraananchai S, Oanh LN, Tucker J, Kurniati N, Hansudewechakul R, et al. Impact of orphan status on HIV treatment outcomes and retention in care of children and adolescents in Asia. J Virus Erad. 2016;2(4):227-31.

20. Urassa DP, Matemu S, Sunguya BF. Antiretroviral therapy clinic attendance among children aged 0-14 years in Kahama district, Tanzania: a crosssectional study. Tanzan J Health Res. 2018;20(1). https://www.ajol.info/index. php/thrb/article/view/162229/157223.

21. Williams M(M), Van Rooyen DRM, Ricks EJ. Accessing antiretroviral therapy for children: Caregivers' voices. Health SA Gesondheid. 2016;21:331-8.

22. Gichane MW, Sullivan KA, Shayo AM, Mmbaga BT, O'Donnell K, Cunningham CK, et al. Caregiver role in HIV medication adherence among HIV-infected orphans in Tanzania. AIDS Care. 2018;30(6):701-5.

23. Hendrickson C, Evans D, Brennan AT, Patz S, Untiedt S, Bassett J, et al. Treatment outcomes among HIV-positive orphaned and non-orphaned children on antiretroviral therapy in Johannesburg, South Africa. S Afr Med J. 2019;109(9):679-85.

24. Vreeman R, Wiehe S, Ayaya S, Musick B, Nyandiko W. Association of antiretroviral and clinic adherence with orphan status among HIVinfected children in western Kenya. J Acquir Immune Defic Syndr 1999. 2008:49:163-70.

25. Nyandiko W, Ayaya S, Nabakwe E, Tenge C, Sidle J, Yiannoutsos C, et al. Outcomes of HIV-infected orphaned and non-orphaned children on antiretroviral therapy in western Kenya. J Acquir Immune Defic Syndr 1999 2007:43:418-25

26. Kikuchi K, Poudel KC, Muganda J, Majyambere A, Otsuka K, Sato T, et al. High risk of ART non-adherence and delay of ART initiation among HIV positive double orphans in Kigali, Rwanda. PLoS One. 2012;7(7):e41998.

27. Humphrey JM, Genberg BL, Keter A, Musick B, Apondi E, Gardner A, et al. Viral suppression among children and their caregivers living with HIV in western Kenya. J Int AIDS Soc. 2019;22(4):e25272.

28. Kuo C, Operario D. Caring for AIDS-orphaned children: an exploratory study of challenges faced by carers in KwaZulu-Natal, South Africa. Vulnerable Child Youth Stud. 2010:5(4):344-52.
29. Heymann J, Earle A, Rajaraman D, Miller C, Bogen K. Extended family caring for children orphaned by AIDS: balancing essential work and caregiving in a high HIV prevalence nations. AIDS Care. 2007;19(3):337-45.

30. Miller CM, Gruskin S, Subramanian SV, Rajaraman D, Heymann SJ. Orphan care in Botswana's working households: growing responsibilities in the absence of adequate support. Am J Public Health. 2006;96(8):1429-35.

31. Rajaraman D, Earle A, Heymann SJ. Working HIV care-givers in Botswana: spill-over effects on work and family well-being. Community Work Fam. 2008;11(1):1-17.

32. Thielman N, Ostermann J, Whetten K, Whetten R, O'Donnell K, Positive Outcomes for Orphans Research Team. Correlates of poor health among orphans and abandoned children in less wealthy countries: the importance of caregiver health. PLoS One. 2012;7(6):e38109.

33. Maundeni T, Malinga-Musamba T. The role of informal caregivers in the well-being of orphans in Botswana: a literature review. Child Fam Soc Work. 2013;18(2):107-16.

34. Ministry of Health, Community Development, Gender, Elderly and Children (MoHCDEC) (Tanzania). National integrated case management training manual for community case workers. 2017. Available from: https:// bantwana.org/wp-content/uploads/2018/07/National-Integrated-CaseManagement-System-Framework_June-2018.pdf.

35. PEPFAR. Monitoring, evaluation, and reporting indicator reference guide. MER 2.0 (Version 2.4); 2019. p. 251. Available from: https://www.state.gov/ wp-content/uploads/2019/10/PEPFAR-MER-Indicator-Reference-GuideVersion-2.4-FY20.pdf. Cited 2020 Apr 1.

36. Ministry of Health, Community Development, Gender, Elderly and Children (MoHCDEC) (Tanzania). National integrated case management system framework. 2017. Available from: https://bantwana.org/wp-content/ uploads/2018/07/National-Integrated-Case-Management-SystemFramework_June-2018.pdf. Cited 2020 Apr 1.

37. USAID Kizazi Kipya Project Case Management and Child Protection Advisor. Standard operating procedure: case management within the USAID Kizazi Kipya project (version 1). Dar es Salaam: Pact; 2017.

38. Pact. Kizazi Kipya: new generation: Pact; 2019. Available from: http://www. pactworld.org/country/tanzania/project. Cited 2018 Aug 20.

39. Vyas S, Kumaranayake L. Constructing socio-economic status indices: how to use principal components analysis. Health Policy Plan. 2006;21(6):459-68.

40. Snijders $T A B$, Bosker RJ. Multilevel analysis: an introduction to basic and advanced multilevel modeling. London: SAGE; 2011. p. 370.

41. University of Bristol. What are multilevel models and why should I use them? 2018. Available from: http://www.bristol.ac.uk/cmm/learning/ multilevel-models/what-why.html. Cited 2018 Jan 31.

42. Koo TK, Li MY. A guideline of selecting and reporting intraclass correlation coefficients for reliability research. J Chiropr Med. 2016;15(2):155-63.

43. Rodriguez $\mathrm{G}$, Elo I. Intra-class correlation in random-effects models for binary data. Stata J. 2003;3(1):32-46.

44. Pourhoseingholi MA, Baghestani AR, Vahedi M. How to control confounding effects by statistical analysis. Gastroenterol Hepatol Bed Bench. 2012;5(2):79-83.

45. Kahlert J, Gribsholt SB, Gammelager H, Dekkers OM, Luta G. Control of confounding in the analysis phase - an overview for clinicians. Clin Epidemiol. 2017;9:195-204

46. McNamee R. Regression modelling and other methods to control confounding. Occup Environ Med. 2005;62(7):500-6.

47. Murray KW, Duggan A. Understanding confounding in research. Pediatr Rev. 2010;31(3):124-6.

48. Scully EP. Sex differences in HIV infection. Curr HIV/AIDS Rep. 2018; 15(2):136-46,

49. Hilber A, Malungo J, Musheke M, Merten S. Sex differentials in the uptake of antiretroviral treatment in Zambia. AIDS Care. 2014;26(10):1258-62.

50. Purnamawati K, Ong JA-H, Deshpande S, Tan WK-Y, Masurkar N, Low JK, et al. The importance of sex stratification in autoimmune disease biomarker research: a systematic review. Front Immunol. 2018;9:1208.

51. Pacheco PRG, Zara ALSA, Silva e Souza LC, Turchi MD. Late onset of antiretroviral therapy in adults living with HIV in an urban area in Brazil: prevalence and risk factors. J Trop Med. 2019; Available from: https://www. hindawi.com/journals/jtm/2019/5165313/. Cited 2019 Jul 30.

52. Wilson LE, Korthuis T, Fleishman JA, Conviser R, Lawrence PB, Moore RD, et al. HIV-related medical service use by rural/urban residents: a multistate perspective. AIDS Care. 2011;23(8):971-9. 
53. Tromp N, Michels C, Mikkelsen E, Hontelez J, Baltussen R. Equity in utilization of antiretroviral therapy for HIV-infected people in South Africa: a systematic review. Int J Equity Health. 2014;13(1):60.

54. MacKenzie $\sqcup$, Hull MW, Samji H, Lima VD, Yip B, Zhang W, et al. Is there a rural/ urban gap in the quality of HIV care for treatment-naïve HIV-positive individuals initiating antiretroviral therapy in British Columbia? AIDS Care. 2017;29(10):1218-26.

55. Posse M, Baltussen R. Barriers to access to antiretroviral treatment in Mozambique, as perceived by patients and health workers in urban and rural settings. AIDS Patient Care STDs. 2009;23(10):867-75.

56. Maqutu D, Zewotir T, North D, Naidoo K, Grobler A. Determinants of optimal adherence over time to antiretroviral therapy amongst HIV positive adults in South Africa: a longitudinal study. AIDS Behav. 2011;15(7):1465-74.

57. Venables E, Casteels I, Manziasi Sumbi E, Goemaere E. "Even if she's really sick at home, she will pretend that everything is fine.": Delays in seeking care and treatment for advanced HIV disease in Kinshasa, Democratic Republic of Congo. Madiba S, editor. PLoS One. 2019;14(2):e0211619.

58. Fox MP, Mazimba A, Seidenberg P, Crooks D, Sikateyo B, Rosen S. Barriers to initiation of antiretroviral treatment in rural and urban areas of Zambia: a cross-sectional study of cost, stigma, and perceptions about ART. J Int AIDS Soc. 2010;13:8.

59. Patenaude BN, Chimbindi N, Pillay D, Bärnighausen T. The impact of ART initiation on household food security over time. Soc Sci Med. 2018:198:175-84.

60. Mshana GH, Wamoyi J, Busza J, Zaba B, Changalucha J, Kaluvya S, et al. Barriers to accessing antiretroviral therapy in Kisesa, Tanzania: a qualitative study of early rural referrals to the national program. AIDS Patient Care STDs. 2006:20(9):649-57.

61. Chomi EN, Mujinja PG, Enemark U, Hansen K, Kiwara AD. Health care seeking behaviour and utilisation in a multiple health insurance system: does insurance affiliation matter? Int J Equity Health. 2014;13(1):25

62. Robyn PJ, Hill A, Liu Y, Souares A, Savadogo G, Sié A, et al. Econometric analysis to evaluate the effect of community-based health insurance on reducing informal self-care in Burkina Faso. Health Policy Plan. 2012;27(2):156-65.

63. Osei Asibey B, Agyemang S. Analysing the influence of health insurance status on peoples' health seeking behaviour in rural Ghana. J Trop Med. 2017;2017. http://downloads.hindawi.com/journals/jtm/2017/8486451.pdf.

64. Nash D, Tymejczyk O, Gadisa T, Kulkarni SG, Hoffman S, Yigzaw M, et al. Factors associated with initiation of antiretroviral therapy in the advanced stages of HIV infection in six Ethiopian HIV clinics, 2012 to 2013. J Int AIDS Soc. 2016;19(1):20637.

65. Parcesepe AM, Bernard C, Agler R, Ross J, Yotebieng M, Bass J, et al. Mental health and HIV: research priorities related to the implementation and scale up of 'treat all' in sub-Saharan Africa. J Virus Erad. 2018;4(Suppl 2):16.

66. Brandt R. The mental health of people living with HIV/AIDS in Africa: a systematic review. Afr J AIDS Res. 2009;8(2):123-33.

67. Corrigan PW. The stigma of disease and disability: understanding causes and overcoming injustices. Washington D.C.: American Psychological Association; 2014.

68. Chanvilay T, Yoshida Y, Reyer JA, Hamajima N. Factors associated with access to antiretroviral therapy among people living with HIV in Vientiane capital, Lao PDR. Nagoya J Med Sci. 2015;77(1-2):29.

69. Talisuna-Alamo S, Colebunders R, Ouma J, Sunday P, Ekoru K, Laga M, et al. Socioeconomic support reduces nonretention in a comprehensive, community-based antiretroviral therapy program in Uganda. J Acquir Immune Defic Syndr 1999. 2012;59(4):e52-9.

70. Layer EH, Kennedy CE, Beckham SW, Mbwambo JK, Likindikoki S, Davis WW, et al. Multi-level factors affecting entry into and engagement in the HIV continuum of care in Iringa, Tanzania. PLoS One. 2014;9(8):e104961.

71. WHO. Progress report 2016 - prevent HIV, test and treat all: WHO support for country impact: WHO. Available from: https://apps.who.int/iris/bitstream/ handle/10665/251713/WHO-HIV-2016.24-eng.pdf. Cited 2020 Apr 5.

\section{Publisher's Note}

Springer Nature remains neutral with regard to jurisdictional claims in published maps and institutional affiliations.

Ready to submit your research? Choose BMC and benefit from:

- fast, convenient online submission

- thorough peer review by experienced researchers in your field

- rapid publication on acceptance

- support for research data, including large and complex data types

- gold Open Access which fosters wider collaboration and increased citations

- maximum visibility for your research: over $100 \mathrm{M}$ website views per year

At $\mathrm{BMC}$, research is always in progress.

Learn more biomedcentral.com/submissions 